Full length article

\title{
In-situ TEM study of the crystallization sequence in a gold-based metallic glass
}

\author{
Yu.P. Ivanov a,b,*, C.M. Meylan ${ }^{a}$, N.T. Panagiotopoulos ${ }^{a}$, K. Georgarakis ${ }^{c}$, A.L. Greer ${ }^{a, *}$

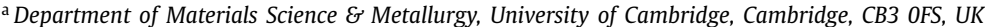

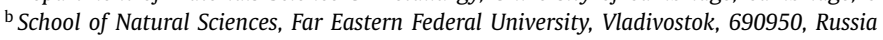 \\ 'School of Aerospace, Transport and Manufacturing, Cranfield University, Cranfield, MK43 OAL, UK
}

\section{A R T I C L E I N F O}

\section{Article history:}

Received 16 April 2020

Revised 4 June 2020

Accepted 12 June 2020

Available online 18 June 2020

\section{Keywords:}

Metallic glass

In-situ transmission electron microscopy

(TEM)

Differential scanning calorimetry (DSC)

Crystallization

Nanocrystalline alloys

\begin{abstract}
A B S T R A C T
The composition $\mathrm{Au}_{49} \mathrm{Ag}_{5.5} \mathrm{Pd}_{2.3} \mathrm{Cu}_{26.9} \mathrm{Si}_{16.3}$ (at.\%) is of interest as the basis for the development of goldbased bulk metallic glasses for application in jewellery. In-situ heating in transmission electron microscopy (TEM) and differential scanning calorimetry (DSC, both conventional and fast) are used to obtain a comprehensive characterization of the decomposition on heating a melt-spun glass of this composition. Linking TEM with DSC over a range of heating rates $0.083-2000 \mathrm{~K} \mathrm{~s}^{-1}$, allows the sample temperature in the TEM heating stage to be calibrated. On heating up to melting, the glass decomposes in up to four stages: (1) complete transformation to single-phase nanocrystalline $(\mathrm{Au}, \mathrm{Cu})_{7} \mathrm{Si}$; (2) grain growth of this phase; (3) precipitation of $(\mathrm{Pd}, \mathrm{Ag}) \mathrm{Si}$, reducing the supersaturation of silicon in the $(\mathrm{Au}, \mathrm{Cu})_{7} \mathrm{Si}$ matrix; (4) with the precipitate phase remaining stable, decomposition of the matrix to a mixture of $(\mathrm{Au}, \mathrm{Ag})_{8} \mathrm{Cu}_{2}$, $\mathrm{AuCu}$ and $\mathrm{Cu}_{3} \mathrm{Au}$ phases. At all stages, grain diameters remain sub-micrometre; some of the stable nanocrystalline microstructures may themselves be of interest for applications. The characterization of the decomposition can assist in the optimization of the glass composition to improve tarnishresistance, while retaining adequate glass-forming ability, formability in thermoplastic processing, and resistance to crystallization. For materials in general, the close correlation of in-situ TEM and DSC results should find wide use in characterizing complex transformation sequences.
\end{abstract}

(c) 2020 Acta Materialia Inc. Published by Elsevier Ltd.

This is an open access article under the CC BY license. (http://creativecommons.org/licenses/by/4.0/)

\section{Introduction}

The first reported metallic glass (MG) formed by rapid solidification had the composition $\mathrm{Au}_{75} \mathrm{Si}_{25}$ (all compositions are given in nominal at.\%) [1]. This alloy has low glass-forming ability (GFA) and the glass has poor thermal stability, crystallizing in $24 \mathrm{~h}$ at room temperature (RT) [1]. Interest in gold-based MGs has increased with the discovery of compositions showing higher GFA that permit bulk formation with minimum crosssection thickness of several $\mathrm{mm}$. In particular, the composition $\mathrm{Au}_{49} \mathrm{Ag}_{5.5} \mathrm{Pd}_{2.3} \mathrm{Cu}_{26.9} \mathrm{Si}_{16.3}$ developed by Schroers et al. has been widely studied: on heating, the alloy has a wide supercooled liquid region suitable for thermoplastic processing [2] and good formability [3]. Its high gold content (76.3 wt.\%), equivalent to more than 18 carat, permits use in jewellery [2], for which it is attractive (as expected in general for a MG) because of its high hardness (relative to crystalline gold alloys) conferring scratch resistance. Un-

\footnotetext{
* Corresponding authors.

E-mail addresses: ii243@cam.ac.uk (Yu.P. Ivanov), alg13@cam.ac.uk (A.L. Greer).
}

fortunately, this MG suffers from fast tarnishing at RT, associated with partitioning of gold and copper, and internal oxidation of silicon [4]. In developing new gold-based MGs with improved tarnishresistance, it is important to understand their crystallization, as the suppression of crystallization is necessary to retain adequate GFA and thermal stability. These properties, and the associated formability in high-temperature thermoplastic processing, are advantageous in practical manufacturing, whether for jewellery or other applications. In addition, crystallization in gold-based glassy systems can improve tarnish-resistance [5], and can allow control of colour [6], while retaining adequate mechanical properties [7].

The crystallization of multi-component bulk gold-based glasses is complex, with several steps. In only a few studies [8-10] (Table 1 ), has there been identification of the crystalline phases formed upon heating of $\mathrm{Au}_{49} \mathrm{Ag}_{5.5} \mathrm{Pd}_{2.3} \mathrm{Cu}_{26.9} \mathrm{Si}_{16.3}$ MG. Not all phases could be characterized and the evolution of the microstructure remains unclear.

Differential scanning calorimetry (DSC) studies [8,9,11], of this MG show several exotherms on heating, the first being dominant. The second exotherm is visible at low heating rate $\Phi(0.017-$ 
Table 1

Phases formed on decomposition of $\mathrm{Au}_{49} \mathrm{Ag}_{5.5} \mathrm{Pd}_{2.3} \mathrm{Cu}_{26.9} \mathrm{Si}_{16.3} \mathrm{MG}$ on heating.

\begin{tabular}{|c|c|c|c|}
\hline Stage I & Stage II & Equilibrium & Notes \\
\hline $\begin{array}{l}\text { up to } 438 \mathrm{~K} \text { : } \\
\text { full devitrification to: } \\
\text { - simple cubic } \\
(a=8.96 \AA)\end{array}$ & $\begin{array}{l}\text { up to } 463 \mathrm{~K} \text { : } \\
\text { - } \mathrm{Cu}_{83} \mathrm{Si}_{17}\end{array}$ & 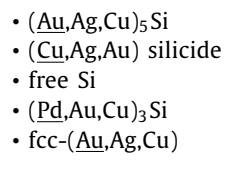 & $\begin{array}{l}\text { In stages I and II, } \\
\Phi=0.017 \mathrm{~K} \mathrm{~s}^{-1} \\
\text { Phase identification by } \\
\text { XRD ( } \& \text { by SEM for } \\
\text { equilibrium) } \\
\text { [8] }\end{array}$ \\
\hline $\begin{array}{l}\text { up to } 423 \mathrm{~K}: \\
\text { - } \mathrm{Au}_{3} \mathrm{Cu} \\
\text { - } \mathrm{AuCu}_{3} \\
\text { - } \mathrm{AuCu}\end{array}$ & $\begin{array}{l}\text { up to } 448-503 \mathrm{~K}: \\
\text { - } \mathrm{Au}_{2} \mathrm{Si} \\
\text { - } \mathrm{Pd}_{x} \mathrm{Si}_{y} \\
\text { - } \mathrm{PdCu} \\
\text { - } \mathrm{Cu}_{4} \mathrm{Si}\end{array}$ & & $\begin{array}{l}\text { In I and II, average } \\
\Phi=0.017 \mathrm{~K} \mathrm{~s}^{-1} \\
\text { Phase identification by } \\
\text { XRD } \\
{[9]}\end{array}$ \\
\hline $\begin{array}{l}\text { devitrification onset } \\
\text { up to } 563 \mathrm{~K} \text { : } \\
\text { - AuCu nanocrystals }\end{array}$ & & & $\begin{array}{l}\Phi=3000 \mathrm{~K} \mathrm{~s}^{-1} \\
\text { Phase identification by } \\
\text { SAED } \\
{[10]}\end{array}$ \\
\hline
\end{tabular}

$\left.0.083 \mathrm{~K} \mathrm{~s}^{-1}[8,9]\right)$. At $\Phi=0.333 \mathrm{~K} \mathrm{~s}^{-1}$, two further exotherms are distinguishable (though barely so) before the melting endotherm [11]. In contrast, the DSC trace in ref. [2] presents only one relatively broad exotherm. The traces with several exotherms were measured for samples from melt-spun ribbons $[8,10,11]$ and from a $2 \mathrm{~mm}$-thick plate [9], whereas the single-exotherm trace is from a 5-mm-diam. rod. In any case, the composition $\mathrm{Au}_{49} \mathrm{Ag}_{5.5} \mathrm{Pd}_{2.3} \mathrm{Cu}_{26.9} \mathrm{Si}_{16.3}$ presents complex crystallization behaviour, with phases not yet fully identified.

We identify the phases formed upon heating an $\mathrm{Au}_{49} \mathrm{Ag}_{5.5} \mathrm{Pd}_{2.3} \mathrm{Cu}_{26.9} \mathrm{Si}_{16.3}$ MG ribbon using in-situ transmission electron microscopy (TEM). Recent advances in this technique permit a thin-foil sample to be heat-treated inside the TEM column with stable temperature and position in holders developed using MEMS technology [12]. Using such holders, imaging and spectroscopy in combination permit detailed characterization of the solid-state transformations in MGs upon heating.

\section{Experimental details}

\subsection{Preparation of the metallic glass}

A master alloy $\mathrm{Au}_{49} \mathrm{Ag}_{5.5} \mathrm{Pd}_{2.3} \mathrm{Cu}_{26.9} \mathrm{Si}_{16.3}$ ingot was produced by melting high-purity elements (99.9\% or better) together in an arcmelter under argon atmosphere using titanium as an oxygen getter. The ingot was inverted and remelted five times to ensure chemical homogeneity. Ribbons of $40 \mu \mathrm{m}$ thickness were produced from the arc-melted ingot by melt-spinning on a rotating copper wheel (peripheral speed $33 \mathrm{~m} \mathrm{~s}^{-1}$ ) under a helium atmosphere.

The present study of the ribbon was carried out eight years after it was melt-spun. X-ray diffraction just after production, and again after eight years, shows that the ribbon is glassy (Suppl. Mater. Fig. S1). There are, however, isolated crystals embedded in the ribbon (Fig. S2); these are several micrometres in diam. and too large to have grown during the melt-spinning. Consistent with the Bragg peaks (Fig. S1), the crystals are presumed to be palladium silicides. These are known to form easily and to be difficult to dissolve on re-melting [5]. The comparison of X-ray diffractograms (Fig. S1) shows no evidence of any change in the degree of crystallinity. The age of the ribbon permits study of a MG that is exceptionally well relaxed.

\subsection{Differential scanning calorimetry}

Conventional differential scanning calorimetry (CDSC), with heating rates $\Phi$ from 0.083 to $3 \mathrm{~K} \mathrm{~s}^{-1}$, was carried out in a Q2000 DSC (TA Instruments). The samples, of typical mass $10-15 \mathrm{mg}$, were encapsulated in aluminium pans with lids, and the system was flushed with nitrogen at $50 \mathrm{ml} \mathrm{min}^{-1}$. In fast (flash) FDSC, samples of estimated mass $1 \mu \mathrm{g}$ were heated at 2 to $2000 \mathrm{~K} \mathrm{~s}^{-1}$ in a Flash DSC 1 (Mettler-Toledo) with UFS 1 sensors and flushed with nitrogen at $30 \mathrm{ml} \mathrm{min}{ }^{-1}$.

In the CDSC measurements, samples were heated from $173 \mathrm{~K}$ to $773 \mathrm{~K}$ (well beyond melting), before being cooled back to $173 \mathrm{~K}$, followed by a second heating run at the same $\Phi$ in order to obtain the baseline. In the FDSC measurements, samples were heated from $233 \mathrm{~K}$ to $773 \mathrm{~K}$, held at $773 \mathrm{~K}$ for $0.1 \mathrm{~s}$ and then cooled at $100 \mathrm{~K} \mathrm{~s}^{-1}$, followed similarly by a second heating run, measured at the same $\Phi$ as the first, to obtain the baseline. In both CDSC and FDSC, the sample was fully crystallized as a result of the first heating and cooling cycle, allowing the second run to establish a consistent baseline. In FDSC, the observed onset of melting of the re-solidified material (at $T_{\mathrm{m}}$, re-sol $=625 \mathrm{~K}$ ) provides a useful calibration of the sample temperature, correcting for possible thermal lags, especially at high $\Phi . T_{\mathrm{m} \text {, re-sol }}$ is higher than the melting temperature $T_{\mathrm{m}}=618 \mathrm{~K}$ on first heating the MG; this difference is discussed in $\S 4.4$.

FDSC was also used to pre-treat samples for TEM characterization. Samples were heated from $233 \mathrm{~K}$ to an upper temperature $\left(518 \mathrm{~K}\right.$ or $578 \mathrm{~K}$ ) at $100 \mathrm{~K} \mathrm{~s}^{-1}$, held isothermally for $0.1 \mathrm{~s}$, then cooled back to $233 \mathrm{~K}$ at a rate of $4000 \mathrm{~K} \mathrm{~s}^{-1}$. Two samples per upper temperature were prepared; one was kept for TEM observation, and the other was heated again in FDSC at a rate of $100 \mathrm{~K} \mathrm{~s}^{-1}$ to observe the heat-flow trace.

\subsection{Transmission electron microscopy}

A cross-sectional specimen with a final thickness of 50-100 nm was prepared by FIB milling using a Helios Nanolab FIB/SEM (Thermo Fisher Scientific). This specimen was transferred from the ribbon sample to a windowed point on a chip (DENSsolutions). A thin layer of platinum $(200 \mathrm{~nm})$ was deposited over the target area using the electron beam ( $2 \mathrm{nA}, 5 \mathrm{kV}$ ) prior to ion-beam exposure. A standard in-situ procedure was adopted for lift-out. Initial setup began with deposition of platinum $(12 \times 2 \times 2.5) \mu \mathrm{m}^{3}$ using the $\mathrm{Ga}^{+}$beam, followed by coarse milling steps using a $30 \mathrm{kV} / 9$ nA beam to remove most of the material. The sample was further thinned to a thickness of $\sim 1.0 \mu \mathrm{m}$ using a $30 \mathrm{kV} / 1.5 \mathrm{nA}$ beam and then undercut in preparation for release. Lift-out was achieved by fixing the specimen to an Omni probe needle using platinum, releasing with a FIB cut, and then lifting out with the stage at $0^{\circ}$ tilt. Once clear of the bulk material, the specimen was fixed on the standard Omni grid orientated initially at $45^{\circ}$ to the electron beam. This allows the lift-out process to be continued later by fix- 
ing the specimen again to an Omni probe needle with in-plane orientation (at $90^{\circ}$ to the initial specimen orientation). The sample was secured on the chip with the stage at $45^{\circ}$ tilt (in-plane to the chip membrane) with ion-beam-deposited platinum. The chip was then re-orientated with the stage at $10-16^{\circ}$ for thinning of the lamella. Further thinning was performed at $30 \mathrm{kV} / 300-100 \mathrm{pA}$, until the platinum appeared transparent in a $5 \mathrm{kV}$ electron-beam image, indicating a thickness of $\sim 150 \mathrm{~nm}$. Final polishing was at a reduced voltage of $2 \mathrm{kV}$ to further thin the lamella to final electron transparency at $3 \mathrm{kV}$ electron energy. This procedure minimizes the amount of damaged material and reduces the levels of implanted gallium in the final thin foil.

The image acquisition and spectroscopic analysis were conducted using a Tecnai Osiris TEM/STEM (FEI) with field-emission gun operated at $200 \mathrm{keV}$, equipped with a Super-X windowless EDX detector. In-situ imaging at high temperatures up to $773 \mathrm{~K}$ was conducted using an in-situ heating holder (DENSsolutions). The resistance of the platinum coil in the chip is monitored in a four-point configuration, and the temperature is calculated using calibration constants provided by the manufacturer. On the heating holder, the sample temperature can be controlled with temperature accuracy $>95 \%$, temperature homogeneity $>99.5 \%$ and thermal stability $0.005 \mathrm{~K}$, and the heating is under the usual TEM vacuum $\left(<10^{-6} \mathrm{~Pa}\right)$. The profile of nominal temperature vs time (Fig. A1) is calibrated (Fig. S3) using the transformation temperatures measured in DSC (Appendix). Between the steps (isothermal holds), the temperature ramp had a duration of $\sim 0.3 \mathrm{~s}$. The specimen was held at each step for at least 2 min to reach thermal equilibrium. At selected temperatures (related to our DSC data) the chemical composition was analysed using the EDX detector, and/or time-series data of HAADF STEM images were recorded with an acquisition time of $1 \mathrm{~s}$. Due to the absence of thermal drift, data acquisition could be started immediately after each temperature increase.

The volume fraction of the silicide particles was estimated by the standard particle analysis of the corresponding HAADF images in the Digital Micrograph software. The thickness of the sample in the area of interest was estimated to be $50 \pm 5 \mathrm{~nm}$.

\section{Results}

\subsection{Differential scanning calorimetry}

Example heat-flow traces measured at different heating rates (by CDSC and FDSC) are shown in Fig. 1. At low heating rates $\Phi$, there is a small endothermic peak just below the glass-transition temperature $\left(T_{\mathrm{g}}\right)$, for example at $\sim 380 \mathrm{~K}$ for $\Phi=0.083 \mathrm{~K} \mathrm{~s}^{-1}$. This sub- $T_{g}$ endotherm is characteristic of annealed, well-relaxed glasses and is expected in the present case. It corresponds to the disordering of relaxed zones [13-15]. The sub- $T_{g}$ peak overlaps with the glass transition at higher heating rates and develops into an overshoot.

In agreement with earlier studies, the first and main exotherm is followed by up to three more exotherms before the onset of melting at $618 \mathrm{~K}$. The positions of the exotherm maxima shift with $\Phi$ as shown in Fig. 2. From earlier studies, the first exotherm corresponds to crystallization. At $\Phi=0.167 \mathrm{~K} \mathrm{~s}^{-1}$, this exotherm has its maximum at $T_{\mathrm{x} 1}=446 \mathrm{~K}$, slightly lower than earlier reported values, e.g. $452 \mathrm{~K}$, at the same $\Phi[16]$. Using the Kissinger method $[17,18]$, for which the standard plot is in the form of Fig. 2, an effective activation energy $Q$ of the first crystallization can be evaluated from the shift of $T_{\mathrm{x} 1}$ as a function of $\Phi$. For $\Phi$ up to $200 \mathrm{~K} \mathrm{~s}^{-1}$, the derived value of $Q$ is $184 \pm 6 \mathrm{~kJ} \mathrm{~mol}^{-1}$, higher than reported values of $161-162 \mathrm{~kJ} \mathrm{~mol}^{-1}[16,19]$. These differences may be due to deviation of the present sample from the nominal composition, related to the undissolved palladium silicides (Fig. S2). The properties of this near-eutectic system may be particularly sensitive to

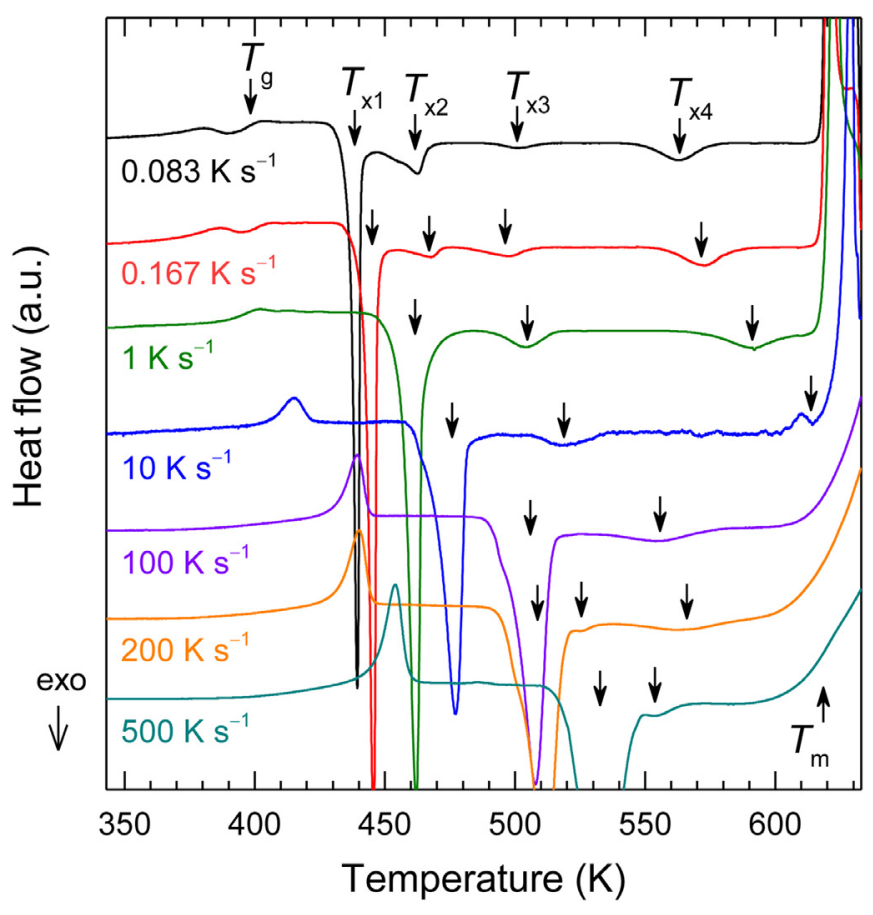

Fig. 1. Examples of thermograms for melt-spun $\mathrm{Au}_{49} \mathrm{Ag}_{5.5} \mathrm{Pd}_{2.3} \mathrm{Cu}_{26.9} \mathrm{Si}_{16.3} \mathrm{MG}$ ribbon measured on continuous heating at rates of $0.083-1 \mathrm{~K} \mathrm{~s}^{-1}$ by CDSC and at $10-500 \mathrm{~K} \mathrm{~s}^{-1}$ by FDSC. The characteristic temperatures for the glass transition $\left(T_{\mathrm{g}}\right)$, transformation peaks $\left(T_{\mathrm{x}}\right)$ and melting onset $\left(T_{\mathrm{m}}\right)$ are indicated by the arrows. To facilitate comparison of the thermograms, they have been scaled such that the glasstransition step height is approximately the same for all heating rates.

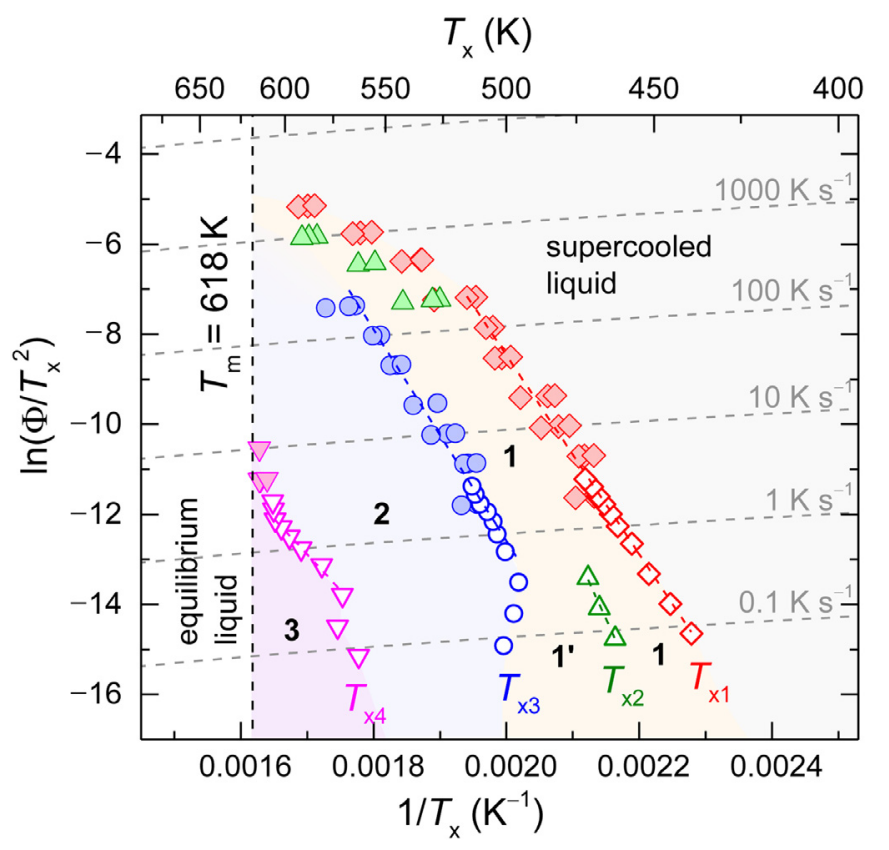

Fig. 2. Kissinger plots of the temperatures $\left(T_{\mathrm{x}}\right)$ of the maxima of the four exotherms observed on heating $\mathrm{Au}_{49} \mathrm{Ag}_{5.5} \mathrm{Pd}_{2.3} \mathrm{Cu}_{26.9} \mathrm{Si}_{16.3} \mathrm{MG}$ at various rates $\Phi$ in CDSC (open symbols) and FDSC (closed symbols). The dashed lines are contours of constant heating rate. The shading indicates regions of different microstructure during heating at a constant rate. In region 1 , the supercooled liquid has crystallized to single-phase nanocrystalline $(\mathrm{Au}, \mathrm{Cu})_{7} \mathrm{Si}$, supersaturated in silicon. In region $1^{\prime}$, this phase has undergone grain growth. In region 2 , a nm-scale dispersion of ( $\mathrm{Pd}, \mathrm{Ag}) \mathrm{Si}$ nanoparticles has formed in the $(\mathrm{Au}, \mathrm{Cu})_{7} \mathrm{Si}$ matrix. In region 3 , the $(\mathrm{Au}, \mathrm{Cu})_{7} \mathrm{Si} \mathrm{ma}-$ trix has decomposed into a three-phase mixture of $(\mathrm{Au}, \mathrm{Ag})_{8} \mathrm{Cu}_{2}, \mathrm{AuCu}$ and $\mathrm{Cu}_{3} \mathrm{Au}$. 

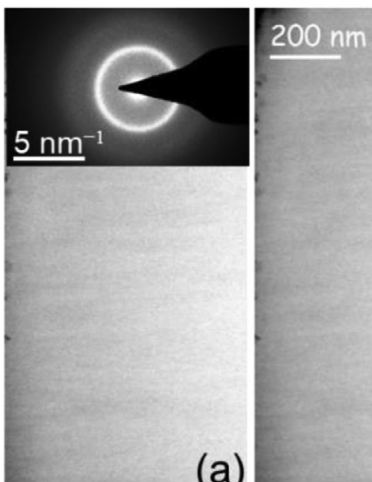

(a)

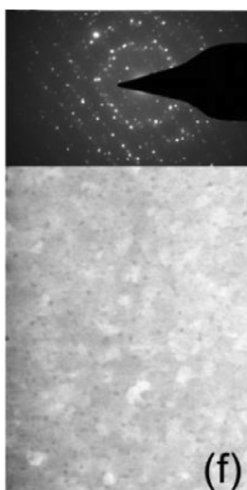

(f)

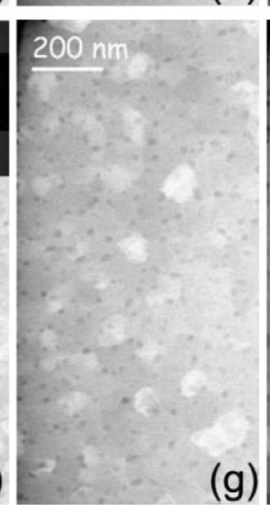

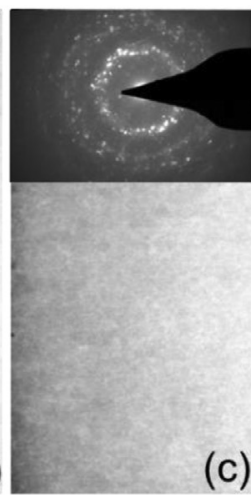

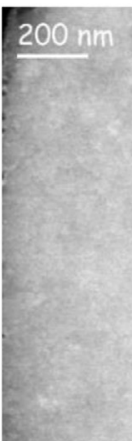

(c)

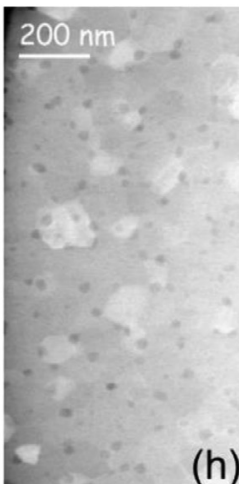

(h)

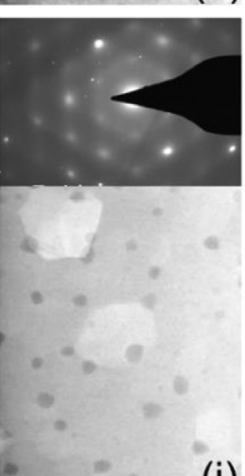

(i)

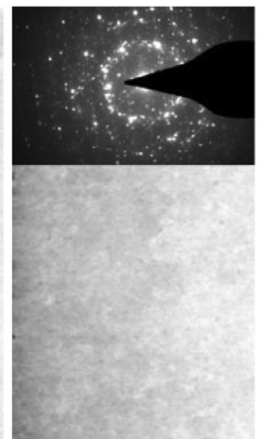

(d)
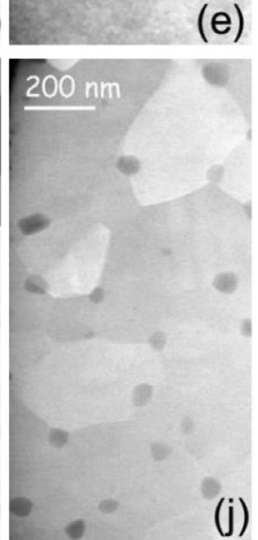

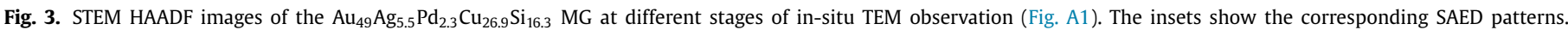

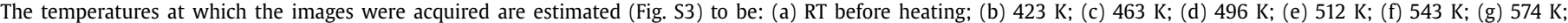
(h) $589 \mathrm{~K}$; (i) $603 \mathrm{~K}$; (j) $618 \mathrm{~K}$.

composition; for example, reported values of the liquidus temperature range from $644 \mathrm{~K} \mathrm{[2]} \mathrm{to} 694 \mathrm{~K}$ [11].

The positions of the later (i.e. higher-temperature) exotherms depend not only on $\Phi$ but also on the previous transformations. This is indicated by the peak temperatures, $T_{\mathrm{x} 3}$ and $T_{\mathrm{x} 4}$ (Fig. 2), which do not increase uniformly with increasing $\Phi$. While the second exotherm is present (for $\Phi \leq 0.333 \mathrm{~K} \mathrm{~s}^{-1}$ ), $T_{\mathrm{x} 3}$ and $T_{\mathrm{x} 4}$ show irregular behaviour, $T_{\mathrm{x} 3}$ in particular shifting to lower values as $\Phi$ is increased. Such behaviour, influenced by the $\Phi$-dependent microstructure of the sample after one or more earlier transformations, does not permit the derivation of any meaningful activation energy using the Kissinger method.

Chen suggested that the rates of the atomic processes in the glass transition and in crystallization should scale with the rate of viscous flow [20]. In a given temperature range, the temperature dependences of the rates should match, such that the various curves in Fig. 2, when shifted vertically, should fall on a single, universal curve. In Chen's study of Pd- and Pt-based MGs, there is a universal curve incorporating viscosity measurements, and DSC measurements of the shift in $T_{\mathrm{g}}$ and in the onset and peak temperatures of the first crystallization peak with $\Phi$. In the present case, as suspected from Fig. 2 and made clear in Fig. S4, the data-sets for $T_{\mathrm{x} 2}, T_{\mathrm{x} 3}$ and $T_{\mathrm{x} 4}$ do not superpose at all well on that for $T_{\mathrm{x} 1}$. The microstructure generated in the first exotherm influences the subsequent transitions, so that their rate is not dependent solely on temperature.

Above $\Phi=10 \mathrm{~K} \mathrm{~s}^{-1}$, the fourth exotherm merges with the melting endotherm. Correspondingly, in Fig. 2, the value of $T_{\mathrm{x} 4}$ curves upwards as it approaches $T_{\mathrm{m}}$. Such upward curvature was predicted in general terms [18] and observed in an earlier FDSC study [19]. For $\Phi>200 \mathrm{~K} \mathrm{~s}^{-1}$, the third exotherm is suppressed, and a small shoulder appears on the high-temperature side of the first exotherm. Finally, for $\Phi \geq 5000 \mathrm{~K} \mathrm{~s}^{-1}$, the first exotherm, and thus all crystallization, is suppressed.

\subsection{Transmission electron microscopy}

Thin foils from the as-cast (melt-spun) alloy (stored for 8 years at RT) show no contrast in HAADF images (e.g. Fig. 3a), indicating a fully glassy structure, also confirmed by SAED (inset, Fig. 3a), and EDX mapping (Fig. 4a) confirms chemical homogeneity. The MG thus shows remarkable stability against crystallization and phase separation over a long time at RT $\left(\approx 74 \%\right.$ of $\left.T_{\mathrm{g}}\right)$. On in-situ heating, holding at $\sim 423 \mathrm{~K}$ for $\sim 2$ min (the first step in the heating profile in Fig. A1) did not induce any detectable change in structure or chemical composition (Fig. 3b), consistent with the DSC measurements (Fig. 1) and literature data $[8,9,21]$. Higher temperatures are approximated by interpolation between calibrated points, as described in the Appendix (Fig. A1, Fig. S3).

On subsequent heating, inhomogeneous contrast develops (Suppl. Mater. Video 1). On holding at $\sim 463 \mathrm{~K}$ (just above $T_{\mathrm{x} 2}$ ) for $>10 \mathrm{~s}$, this is evident in the HAADF image (Fig. 3c) and, with the change in SAED (inset, Fig. 3c), is attributable to the formation of a nanocrystalline phase with grain diam. of 3-15 nm. Since the contrast is weak, we conclude that there is no significant chemical inhomogeneity. EDX mapping (Fig. 4b) confirms that the elemental distribution is nearly as uniform as in the initial glass. Thus the first exotherm in DSC corresponds to complete transformation to a single nanocrystalline phase. Its XRD peaks match those of the recently reported $(\mathrm{Au}, \mathrm{Cu})_{7} \mathrm{Si}$ phase [22]. The structure has the Pearson symbol oP32 (space group Pnma) with lattice parameters dependent on the Cu:Au ratio. In the present case, $a=9.65 \pm 0.02 \AA$, $b=7.62 \pm 0.02 \AA, c=6.89 \pm 0.02 \AA$ (Fig. S5). The calculated powder XRD pattern of this crystalline phase is similar to those reported previously for this MG annealed at the first crystallization peak temperature [8-10], although the suggested phase attributions were different in the earlier works.

On further heating to and holding for $\sim 2 \mathrm{~min}$ at $\sim 496 \mathrm{~K}$ (close to $T_{\mathrm{x} 3}$ ), HAADF imaging (Fig. $3 \mathrm{~d}$ ) shows only coarsening (to 15- 

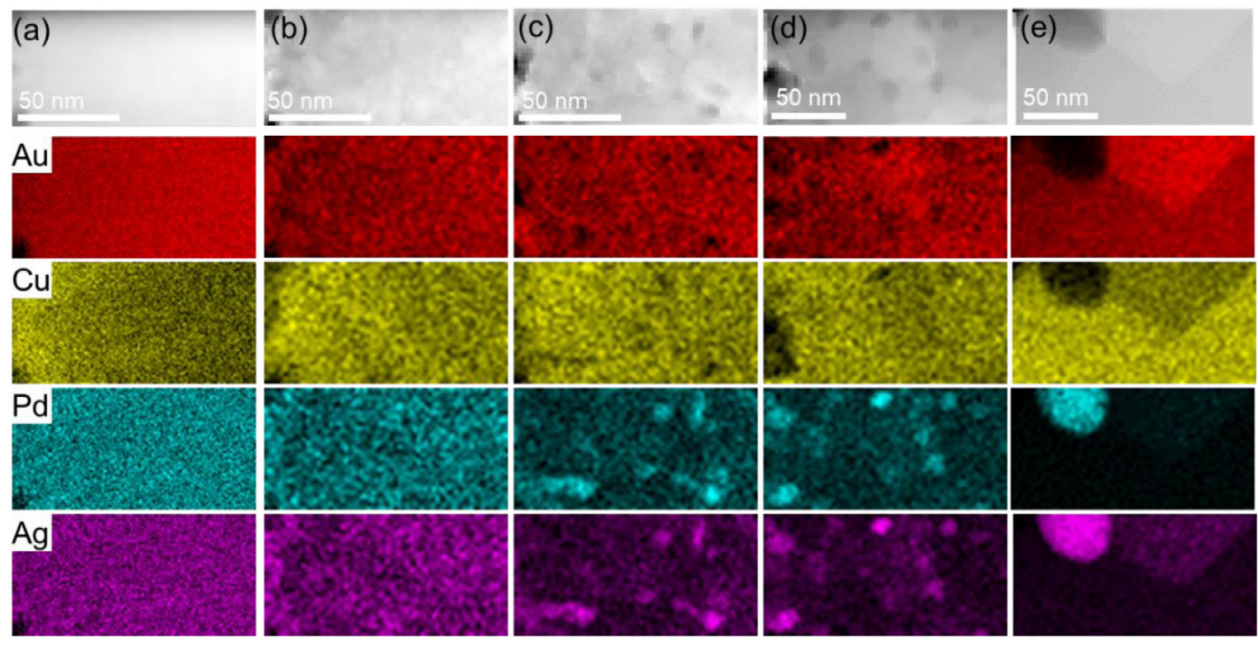

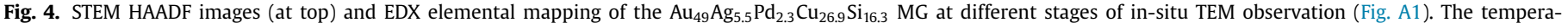
tures at which the images were acquired are estimated (Fig. S3) to be: (a) RT before heating; (b) $463 \mathrm{~K}$; (c) $512 \mathrm{~K}$; (d) $543 \mathrm{~K}$; (e) $603 \mathrm{~K}$.

$30 \mathrm{~nm}$ diam.) of the grains formed in the first exotherm; there is no evidence for decomposition into differing compositions. The weak exotherm with maximum at $T_{\mathrm{x} 2}$, seen in our CDSC traces at low $\Phi$, is thus attributed to grain growth in the polycrystalline $(\mathrm{Au}, \mathrm{Cu})_{7} \mathrm{Si}$ phase.

The exotherm with maximum at $T_{\mathrm{x} 3}$ was studied by heating to $\sim 512 \mathrm{~K}$, when a dispersion of small particles develops, with dark contrast relative to the nanocrystalline matrix (Video 2). This dispersion, after heating to $\sim 512 \mathrm{~K}$, is detected in HAADF imaging (Fig. 3e) and in EDX mapping (Fig. 4c), which shows that the particles (4-8 $\mathrm{nm}$ diam.) are enriched in palladium and silver. The SAED pattern indicates the formation of a silicide phase within the $(\mathrm{Au}, \mathrm{Cu})_{7} \mathrm{Si}$ matrix. The best fitting is for orthorhombic PdSi (B31 structure, space group Pcmn) with $a=5.62 \pm 0.02 \AA$, $b=3.39 \pm 0.02 \AA$ and $c=6.15 \pm 0.02 \AA$ (Fig. S5).

Holding the sample at $\sim 543 \mathrm{~K}$ (between $T_{\mathrm{x} 3}$ and $T_{\mathrm{x} 4}$ ), the microstructure coarsens (Video 3 ). After $\sim 1.5 \mathrm{~min}$ at $\sim 543 \mathrm{~K}$, the grain diameter in the polycrystalline $(\mathrm{Au}, \mathrm{Cu})_{7} \mathrm{Si}$ matrix has increased to 20-40 nm, while the (Pd,Ag)Si particle dispersion is more distinct and the particle diameter has increased to 6-12 nm (Fig. 3f, Fig, 4d). After the fourth exotherm, on heating to $\sim 574 \mathrm{~K}$ and beyond, there is increasing contrast between grains, indicating significant differences in composition (Video 4). HAADF imaging shows that the grains at $\sim 574 \mathrm{~K}$ (Fig. $3 \mathrm{~g}$ ) coarsen on further heating (Fig. $3 \mathrm{~h}$ ). SAED patterns (Fig. 3i, inset) and EDX data (Fig. 4e) show that the matrix has decomposed into three phases: $(\mathrm{Au}, \mathrm{Ag})_{8} \mathrm{Cu}_{2}, \mathrm{AuCu}$ and $\mathrm{Cu}_{3} \mathrm{Au}$ (Fig. S5). The grain structure of the three-phase matrix coarsens on further heating to $\sim 618 \mathrm{~K}$ (Fig. 3j). The coarsening of the matrix grain structure is accompanied by coarsening of the silicide particles from a few nm ultimately to $30-70 \mathrm{~nm}$ diam. At all stages, the silicide particles are located at the grain boundaries in the polycrystalline matrix. At still higher temperatures, the specimen melts; the liquid front migrating towards the edge of the specimen is transiently pinned by the silicide particles (Video 5).

To further link the calorimetric and structural characterizations of the transformation sequence, samples heated in FDSC were studied by TEM. Samples were heated at $100 \mathrm{~K} \mathrm{~s}^{-1}$ to $518 \mathrm{~K}$ (just beyond $T_{\mathrm{x} 1}$ ) or to $578 \mathrm{~K}$ (just beyond $T_{\mathrm{x} 3}$ ), held briefly, cooled to $233 \mathrm{~K}$ (details in $\$ 2.2$ ), then reheated at $100 \mathrm{~K} \mathrm{~s}^{-1}$ to melting. First heating up to $518 \mathrm{~K}$ takes the sample through the transformation associated with the first exotherm only, so that on the second run this exotherm is absent, but that at $T_{\mathrm{x} 3}$ remains (Fig. $5 \mathrm{a}$ ). First heating up to $578 \mathrm{~K}$ takes the sample through all the transfor-

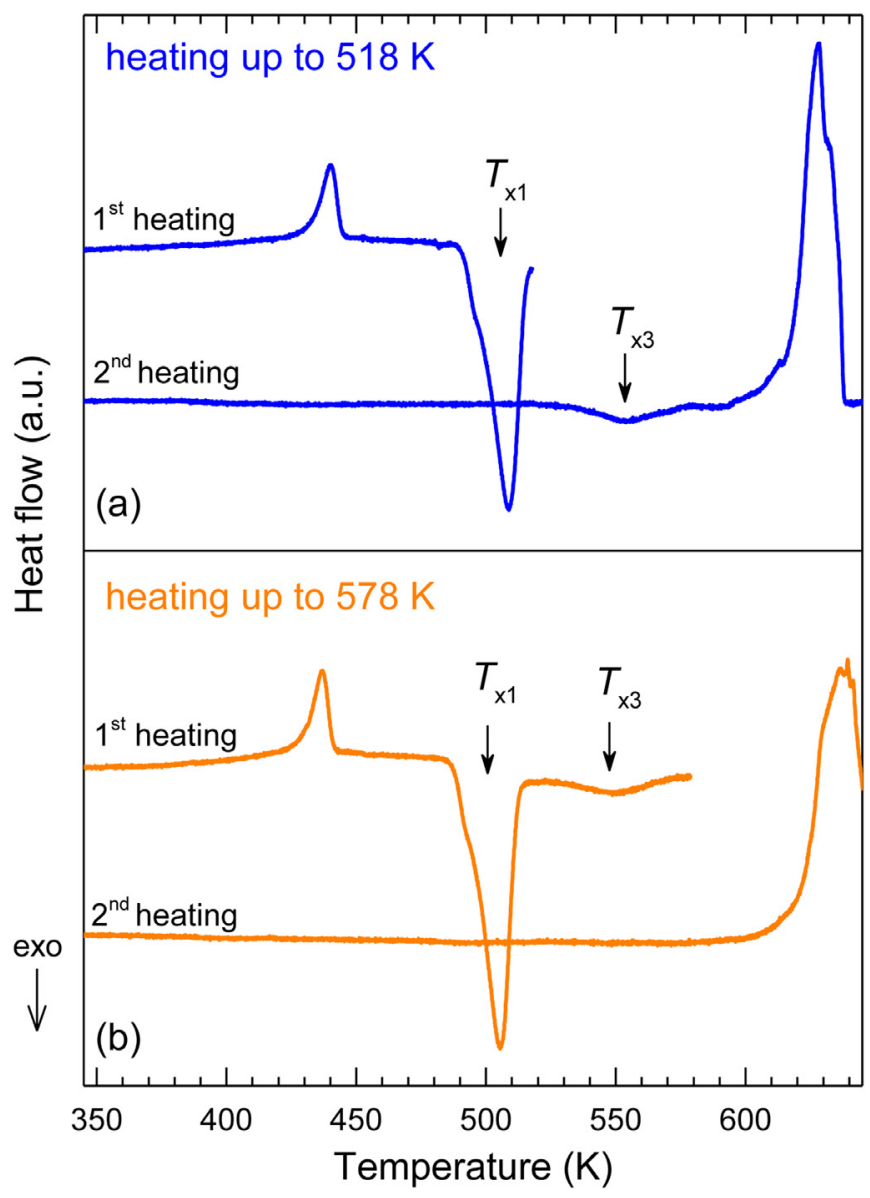

Fig. 5. FDSC thermograms, measured at $100 \mathrm{~K} \mathrm{~s}^{-1}$, of $\mathrm{Au}_{49} \mathrm{Ag}_{5.5} \mathrm{Pd}_{2.3} \mathrm{Cu}_{26.9} \mathrm{Si}_{16.3} \mathrm{MG}$ samples heated to (a) $518 \mathrm{~K}$ and (b) $578 \mathrm{~K}$ and then held isothermally for $0.1 \mathrm{~s}$. The first thermograms to these limiting temperatures are followed by cooling at $4000 \mathrm{~K}$ $\mathrm{s}^{-1}$ to $233 \mathrm{~K}$ and second heating.

mations, so that none is seen on the second run until the sample melts (Fig. 5b).

TEM (HAADF image and corresponding EDX elemental mapping in Fig. 6) shows that the sample pre-heated to $518 \mathrm{~K}$ is chemically homogeneous with a small grain size. In contrast, the sample preheated to $578 \mathrm{~K}$ shows a distinction between a polycrystalline ma- 

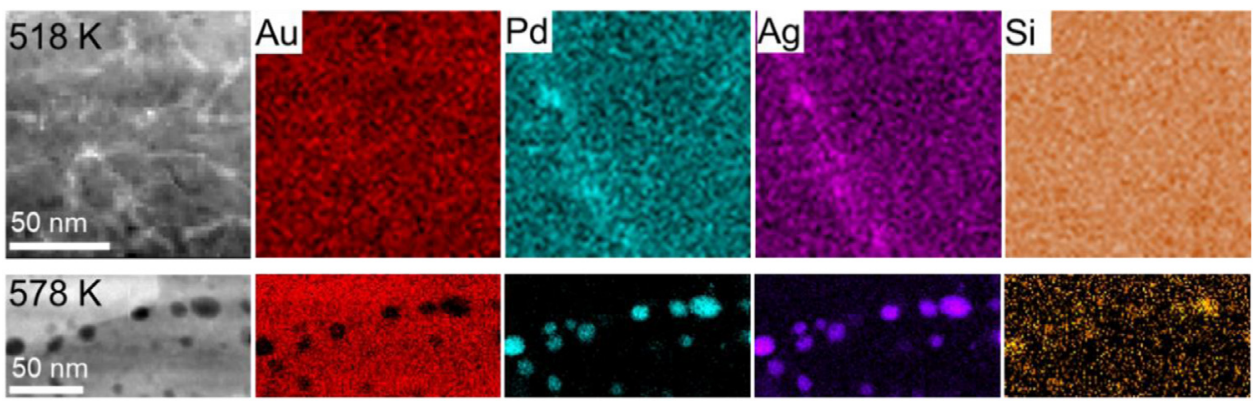

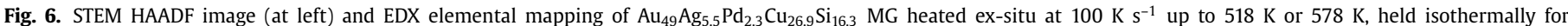
$0.1 \mathrm{~s}$, and then cooled at $4000 \mathrm{~K} \mathrm{~s}^{-1}$. The heat treatments were performed using FDSC (Fig. 5).
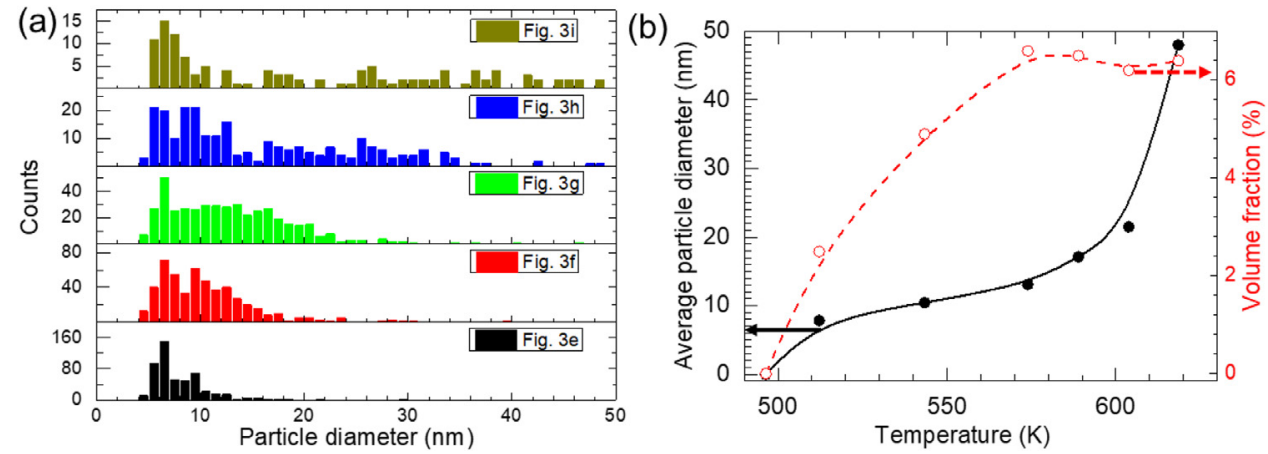

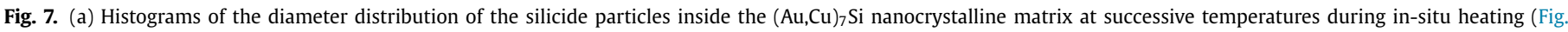
A1); (b) the corresponding evolution of the average silicide particle diameter and of the volume fraction of the silicide phase.

trix enriched in gold and a dispersion of (Pd,Ag)Si particles at the grain boundaries in the matrix. In each case, the microstructure is similar to that found in the in-situ experiment, confirming that the exotherm at $T_{\mathrm{x} 3}$ is associated with the precipitation of ( $\left.\mathrm{Pd}, \mathrm{Ag}\right) \mathrm{Si}$ particles in a nanocrystalline matrix of $(\mathrm{Au}, \mathrm{Cu})_{7} \mathrm{Si}$.

Histograms of the size distribution of those particles, compiled from HAADF images (Fig. 3), show the evolution as the temperature is raised (Fig. 7a) according to the profile in Fig. A1. The average diameter and the volume fraction of the particles (Fig. 7b) evolve as expected for precipitation. The volume fraction grows rapidly at first, slows as the solutes on which the precipitates are based become depleted, and then levels off at a metastableequilibrium value, in this case $\sim 6.4 \%$. Up to $\sim 510 \mathrm{~K}$, the number and diameter of precipitate particles must grow rapidly. Over the range $510 \mathrm{~K}$ to $570 \mathrm{~K}$, the volume fraction rises less than half as much as would be expected from the measured diameter if the particle number were constant. Thus in this temperature range, the number of particles is decreasing, i.e. there must already be coarsening (Ostwald ripening) of the particle distribution. This coarsening is very evident above $570 \mathrm{~K}$, when the particle diameter climbs rapidly at constant volume fraction.

\section{Discussion}

\subsection{Primary crystallization}

Schawe and Löffler studied $\mathrm{Au}_{49} \mathrm{Ag}_{5.5} \mathrm{Pd}_{2.3} \mathrm{Cu}_{26.9} \mathrm{Si}_{16.3} \quad \mathrm{MG}$ formed over a wide range of cooling rates [23]. When formed at lower cooling rates, the MG contained quenched-in nuclei, while these were absent for cooling rates higher than $4000 \mathrm{~K} \mathrm{~s}^{-1}$. The two cases, respectively termed self-doped glass (SDG) and chemically homogeneous glass (CHG) could be clearly distinguished by FDSC studies. The critical $\Phi$ (above which the MG can be heated into the liquid state without crystallization) was $20,000 \mathrm{~K} \mathrm{~s}^{-1}$ for the SDG and $6000 \mathrm{~K} \mathrm{~s}^{-1}$ for the CHG [23]. Song et al. similarly found that suppression of crystallization is more difficult for an MG cooled more slowly [10]. In §3.1, all crystallization is suppressed for $\Phi \geq 5000 \mathrm{~K} \mathrm{~s}^{-1}$, behaviour clearly in the CHG category. Thus (i) the isolated crystallites present in the melt-spun MG ( $\$ 2.1$, Fig. S2) do not affect the behaviour of the glassy phase itself, and (ii) the melt-spinning, as expected for its $\Phi$, gives a main glass free from quenched-in nuclei.

Room temperature $(298 \mathrm{~K})$ is $\sim 74 \%$ of $T_{\mathrm{g}}$ for $\mathrm{Au}_{49} \mathrm{Ag}_{5.5} \mathrm{Pd}_{2.3} \mathrm{Cu}_{26.9} \mathrm{Si}_{16.3} \mathrm{MG}$, a high fraction such that normal storage leads to significant relaxation. CDSC of this MG shortly after it was melt-spun, and after two years of storage at RT, showed significant change in the glass transition, but no detectable change (in onset or peak temperature) in the first crystallization exotherm [8]. In the present work, the storage time at RT is eight years, and there is similarly no detectable change in the crystallization behaviour (Fig. S6). It is expected that the state of relaxation of the glass should not affect the crystallization induced by continuous heating: the sample crystallizes after passing through the glass transition during which it should lose any 'memory' of its initial relaxation. It is interesting, though, that even such long ageing does not induce any internal generation of crystal nuclei.

\subsection{Grain growth in nanocrystalline $(\mathrm{Au}, \mathrm{Cu})_{7} \mathrm{Si}$}

The TEM observations in $\$ 3.2$ suggest that the second exotherm, with maximum at $T_{\mathrm{x} 2}$, seen in DSC traces at low $\Phi$, is associated with grain growth in the nanocrystalline $(\mathrm{Au}, \mathrm{Cu})_{7} \mathrm{Si}$ phase generated in the first exotherm. We now check whether the enthalpy has a reasonable value. The energy per mole $\Delta H$ released as a result of grain growth from radius $r_{1}$ to $r_{2}$ is

$\Delta H=\alpha \gamma V\left(\frac{1}{r_{1}}-\frac{1}{r_{2}}\right)$,

where $\alpha$ is a geometrical factor taken here to be (3/2), $\gamma$ is the grain-boundary energy and $V$ is the molar volume. We take $\gamma$ 
to be the energy of a high-angle grain boundary in cubic closepacked gold, approximated as the energy of a simple tilt boundary with $15^{\circ}$ misorientation. With the values of Burgers vector and shear modulus for gold, we estimate $\gamma \approx 1 \mathrm{~J} \mathrm{~m}^{-2}$. We calculate $V=9.5 \times 10^{-6} \mathrm{~m}^{3} \mathrm{~mol}^{-1}$, from the lattice parameters of the $(\mathrm{Au}, \mathrm{Cu})_{7} \mathrm{Si}$ phase measured in the present work. For the range of values observed in Fig. $3 c$ and Fig. 3d, we take $r_{1}=15 \mathrm{~nm}$ and $r_{2}=30 \mathrm{~nm}$. With these numbers, $\Delta H=475 \mathrm{~J} \mathrm{~mol}^{-1}$. This can be only a rough prediction, but it is in reasonable agreement with measured values: $800 \mathrm{~J} \mathrm{~mol}^{-1}$ for $\Phi=0.017 \mathrm{~K} \mathrm{~s}^{-1}$ [8]; and, in the present work, $290 \mathrm{~J} \mathrm{~mol}^{-1}$ for $\Phi=0.083 \mathrm{~K} \mathrm{~s}^{-1}$, and $80 \mathrm{~J} \mathrm{~mol}^{-1}$ for $\Phi=0.167 \mathrm{~K} \mathrm{~s}^{-1}$. Within reasonable estimations, the enthalpy of the second exotherm is entirely consistent with an origin in grain growth alone.

The second exotherm is asymmetric: the high-temperature edge is much steeper than the low-temperature edge, in direct contrast to the expectation for grain growth on heating, as shown by both modelling and experiment [24,25]. In our samples, something must bring grain growth to an abrupt end. We speculate that this is segregation of excess silicon to the grain boundaries. Any tendency to such segregation would become evident only in the later stages of grain growth as the grain-boundary velocity slows. The segregation would then assist the appearance of the ( $\mathrm{Pd}, \mathrm{Ag}) \mathrm{Si}$ precipitates at the boundaries.

The magnitude of $\Delta H$ decreases with increasing $\Phi$, as there is less time for grain growth. Ultimately, the distinct grain-growth regime disappears, as the primary crystallization extends to higher temperatures at higher $\Phi$ (Fig. 1). The grain growth affects later transformations on heating (Fig. 2), as is clear for the next exotherm. The grain growth in the nanocrystalline $(\mathrm{Au}, \mathrm{Cu})_{7} \mathrm{Si}$ at the lowest $\Phi$ reduces the grain-boundary area per unit volume, and grain boundaries are likely to be the preferred nucleation sites for the $(\mathrm{Pd}, \mathrm{Ag}) \mathrm{Si}$ precipitates. Thus the grain growth inhibits the precipitation, and there is a similar effect on the decomposition of $(\mathrm{Au}, \mathrm{Cu})_{7} \mathrm{Si}$ into three phases around $T_{\mathrm{x} 4}$.

\subsection{Precipitation of (Pd,Ag)Si}

The metal (M)-to-silicon atomic ratio in stoichiometric $(\mathrm{Au}, \mathrm{Cu})_{7} \mathrm{Si}$ is $7: 1$, while, in the nominal-composition alloy, M:Si is $5.135: 1$. Thus the single phase that forms in the first exotherm must be supersaturated in silicon. The supersaturation can be relieved by precipitating $\mathrm{PdSi}$, which is the most silicon-rich of the possible silicides in the quinary alloy. If the precipitation led to an equilibrium mixture of $\mathrm{M}_{7} \mathrm{Si}$ and $\mathrm{MSi}$, then the atomic fraction of the precipitate phase would be $10.1 \%$. There is not enough palladium in the alloy to achieve that, and the EDX mapping (Figs. 4 and 6) suggests that the precipitate incorporates silver; a $10.1 \%$ atomic fraction would be achieved with a composition of $\left(\mathrm{Pd}_{46} \mathrm{Ag}_{54}\right)_{7} \mathrm{Si}$. Silver itself is not a silicide-former, and it seems that the actual metastable equilibrium is reached with less silver in the precipitate, and therefore with residual supersaturation of silicon in the matrix. Compensating for the different volumes per atom in $\mathrm{M}_{7} \mathrm{Si}$ and $\mathrm{MSi}$, an atomic fraction of $10.1 \%$ corresponds to a precipitate volume fraction of $9.3 \%$, in contrast to the observed fraction of $6.4 \%$. Thus the supersaturation of silicon in the $(\mathrm{Au}, \mathrm{Cu})_{7} \mathrm{Si}$ phase is reduced to about one-third of its initial value by the precipitation of $(\mathrm{Pd}, \mathrm{Ag}) \mathrm{Si}$.

\subsection{Decomposition of $(\mathrm{Au}, \mathrm{Cu})_{7} \mathrm{Si}$ into three phases}

The area of the fourth exotherm (at $T_{\mathrm{x} 4}$, Fig. 1) is small: e.g. for $\Phi=0.083 \mathrm{~K} \mathrm{~s}^{-1}, \Delta H=340 \mathrm{~J} \mathrm{~mol}^{-1}$, compared to $1.92 \mathrm{~kJ} \mathrm{~mol}^{-1}$ for primary crystallization and $5.39 \mathrm{~kJ} \mathrm{~mol}^{-1}$ for melting. This reflects a low driving force for this decomposition.
In $\S 2.2$, it was noted that the melting temperature in FDSC is higher ( $625 \mathrm{~K}$ vs $618 \mathrm{~K}$ ) on second heating (after melting and resolidification) than on first heating. The three-phase mixture formed on first heating has an ultimate grain radius of $175 \mathrm{~nm}$ (Fig. 3j); the microstructure on second heating (formed on cooling the liquid rather than on heating the MG) is much coarser. Using Eq. (1), taking the value of $175 \mathrm{~nm}$, a grain-boundary energy of $\sim 1 \mathrm{~J} \mathrm{~m}^{-2}$ (as in $\$ 4.2$ ), and an entropy of fusion for this composition of $8.14 \mathrm{~J}$ $\mathrm{mol}^{-1} \mathrm{~K}^{-1}$ [26], the coarse microstructure on second heating would have a melting point $\sim 10 \mathrm{~K}$ higher than the sub- $\mu \mathrm{m}$ grains that melt on first heating at ultra-fast rates, and apparently also at the lower rates in CDSC.

\subsection{Zener pinning and the stability of the $(\mathrm{Pd}, \mathrm{Ag})$ Si phase}

A dispersion of second-phase particles in a polycrystalline matrix can set an upper limit to the extent of grain growth in the matrix through Zener pinning of the grain boundaries. The maximum mean grain diameter $D_{\max }$ that can be reached is given by

$D_{\max }=\frac{4 r}{3 f}$,

where $r$ is the radius of the dispersed particles and $f$ is the volume fraction of the dispersed phase [27]. The final microstructure in the samples before melting (Fig. 3i,j) has a matrix that has three phases, and grain growth in that matrix might be limited by solute transfer between neighbouring grains of different phases, in which case $D_{\max }$ would be less than the value given by Eq. (2). It is interesting, though, that with, for example, $r \approx 10 \mathrm{~nm}$ and $D_{\max } \approx$ $220 \mathrm{~nm}$ as seen in Fig. 3i, the matrix grain size is at, or close to the Zener limit. This suggests that the interphase boundaries in the three-phase matrix are rather mobile, by comparison with which the dispersion of silicide particles is stable.

\subsection{Crystallization on cooling the liquid}

It is of interest to compare the sequence of transformations characterized in the present work with the crystallization on cooling the liquid. Slow cooling of the liquid has been used to obtain the presumed equilibrium phase mixture [8] listed in Table 1. This mixture includes mainly silicides and the gold-based face-centred cubic (fcc) solid solution. We have already noted the stability of silicides in processing of melts of the present composition (§2.1, Fig. S1, Fig. S2, and Ref. [5] in which the formation of the fcc solid solution from the melt is also noted). The transformation sequences in the present study, even at the lowest $\Phi$, have still not reached the equilibrium crystalline phase mixture before the onset of melting. In common with the studies of freezing, the stability of silicides is clear (\$4.5). But instead of a single gold-rich fcc solid solution, we have a mixture of $(\mathrm{Au}, \mathrm{Ag})_{8} \mathrm{Cu}_{2}, \mathrm{AuCu}$ and $\mathrm{Cu}_{3} \mathrm{Au}$ phases. The stability of this phase mixture relative to the fcc solid solution merits further study, but is beyond the scope of the present work.

\section{Conclusions}

Using in-situ heating in transmission electron microscopy (still shots and videos), supported by differential scanning calorimetry (conventional CDSC and fast FDSC), we have made the first comprehensive characterization of the decomposition of the $\mathrm{Au}_{49} \mathrm{Ag}_{5.5} \mathrm{Pd}_{2.3} \mathrm{Cu}_{26.9} \mathrm{Si}_{16.3}$ metallic glass developed by Schroers et al. By heating over the range from RT to melting at a wide range of rates $\Phi=0.083-2000 \mathrm{~K} \mathrm{~s}^{-1}$, it is possible to correlate the TEM and DSC studies in detail and thereby to obtain a reliable calibration of the sample temperature on the in-situ heating stage. 
The present study was conducted eight years after the meltspinning of the MG, giving an opportunity to investigate a highly relaxed glass. Calorimetrically, the glass transition is much changed by the long ageing at RT, but the crystallization is unaffected, and the aged glass shows no evidence for any quenched-in or internally generated nuclei.

The decomposition on heating is complex, showing up to four stages, manifested as exotherms on DSC traces. Firstly, at $440 \mathrm{~K}$ to $590 \mathrm{~K}$ depending on $\Phi$, the MG crystallizes to single-phase nanocrystalline $(\mathrm{Au}, \mathrm{Cu})_{7} \mathrm{Si}$ with $3-15 \mathrm{~nm}$ grain diam. At low $\Phi(\leq$ $0.333 \mathrm{~K} \mathrm{~s}^{-1}$ ) this phase undergoes a distinct stage of grain growth to $15-30 \mathrm{~nm}$ diam. DSC measurements confirm that the transformation enthalpy is consistent with grain growth. At $500-580 \mathrm{~K}$, a (Pd,Ag)Si phase precipitates, with $4-8 \mathrm{~nm}$ particle diam., reducing the supersaturation of silicon in the $(\mathrm{Au}, \mathrm{Cu})_{7} \mathrm{Si}$ matrix. While the precipitate phase remains stable, at $565-615 \mathrm{~K}$ the matrix decomposes to a mixture of $(\mathrm{Au}, \mathrm{Ag})_{8} \mathrm{Cu}_{2}$, $\mathrm{AuCu}$ and $\mathrm{Cu}_{3} \mathrm{Au}$ phases, a transformation accompanied by a remarkably small reduction in enthalpy. On further heating, both the three-phase matrix and the $(\mathrm{Pd}, \mathrm{Ag}) \mathrm{Si}$ precipitate phase coarsen. The coarsening in the threephase matrix appears to be largely limited by Zener pinning of the interphase boundaries by the ( $\mathrm{Pd}, \mathrm{Ag}) \mathrm{Si}$ particles. Ultimately, at the onset of melting $(618 \mathrm{~K})$, the grain diameter in the matrix has reached $350 \mathrm{~nm}$, and the mean precipitate diameter has reached $50 \mathrm{~nm}$. For $\Phi>10 \mathrm{~K} \mathrm{~s}^{-1}$, the $(\mathrm{Au}, \mathrm{Cu})_{7} \mathrm{Si}$ matrix remains stable up to melting.

Our identification of the phase(s) formed in the first stage of crystallization differs from earlier work. Electron diffraction patterns in the present work allow a more secure phase identification than was possible in earlier studies based on X-ray diffraction, and our identified primary phase, $(\mathrm{Au}, \mathrm{Cu})_{7} \mathrm{Si}$, has been reported only recently. This phase and the precipitate $(\mathrm{Pd}, \mathrm{Ag}) \mathrm{Si}$ are both stable and retain characteristic length scales well under one micrometre. In the final stages of heating, the (Pd,Ag)Si particles are seen to transiently pin the melting front. Microstructures based on these phases formed by devitrification should be studied as an alternative to the monolithic metallic glass for some applications.

The present study may assist in the development of gold-based MGs for jewellery, where the need to improve tarnish-resistance, probably at the expense of GFA and stability against crystallization, highlights the need for better understanding of crystallization.
The complex sequence of transformations analysed in the present study is typical for crystallization of multicomponent MGs, and shows the limitations of conventional studies based on postanneal structural characterization. Reliable phase identification by the local structural and compositional characterization in TEM, and examination in-situ, including videos, is critical in elucidating the sequence of events. The use of calorimetry over a wide range of heating rate allows for efficient use of the TEM results to characterize the kinetics of microstructural change over a range of temperature. Close correlation of TEM and calorimetry allows secure calibration of the temperature in the in-situ experiments, and strengthens the interpretation of the structural changes by matching to observed heats. This combined approach can find use in characterizing a wide range of transformation sequences, not just in MGs.

\section{Declaration of Competing Interest}

The authors declare that they have no known competing financial interests or personal relationships that could have appeared to influence the work reported in this paper.

\section{Acknowledgments}

ALG, CMM, YPI and NTP acknowledge support from the European Research Council under the European Union's Horizon 2020 research and innovation programme (grant ERC-2015-AdG695487: Extend Glass). KG acknowledges support from the HEIFCranfield project on BMGs. The authors thank O.S. Houghton for experimental assistance and for useful discussions.

\section{Supplementary materials}

Supplementary material associated with this article can be found, in the online version, at doi:10.1016/j.actamat.2020.06.021.

\section{APPENDIX: Calibration of the in-situ heating profile}

Fig. 2 provides a map of the sequence of transformations as a function of heating rate $\Phi$. The heating profile for the in-situ TEM (Fig. A1) shows a range of averaged $\Phi$, from $\sim 1 \mathrm{~K} \mathrm{~s}^{-1}$ for

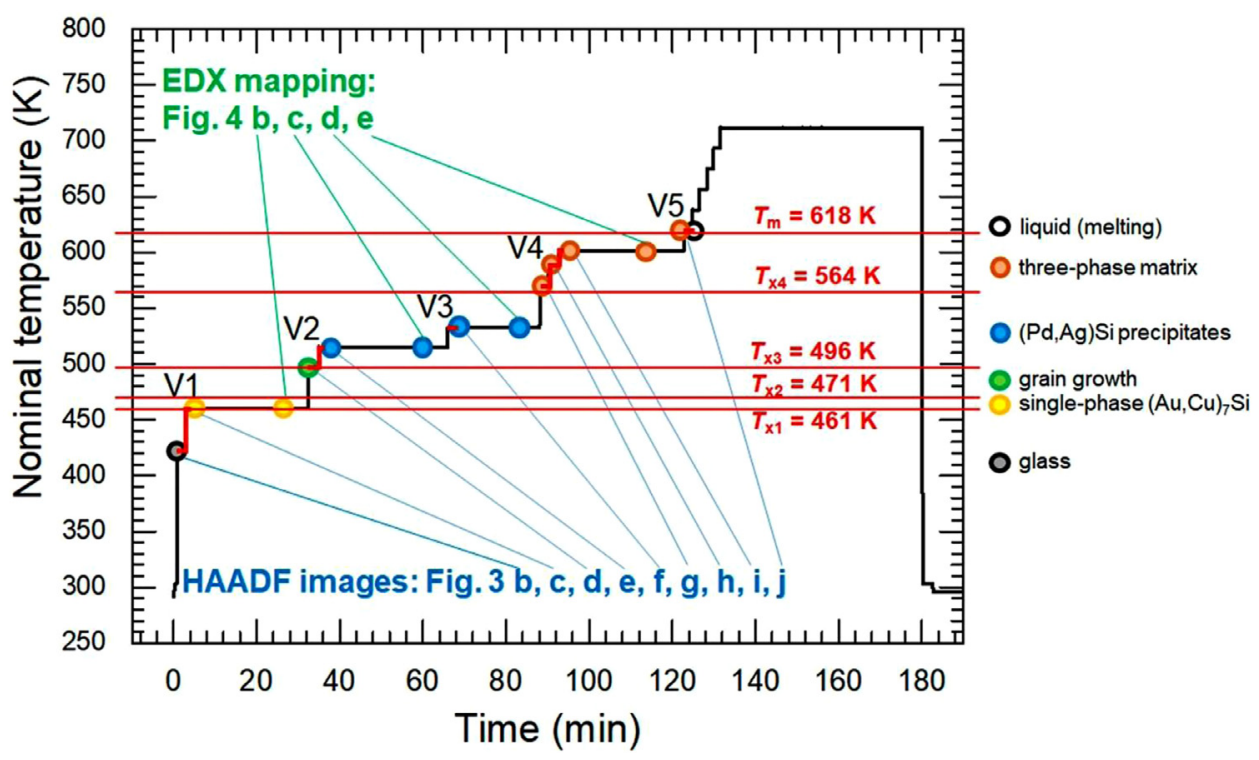

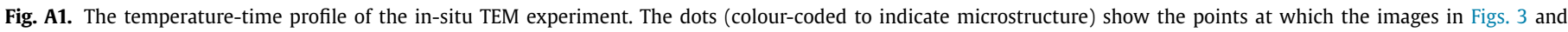
4 were taken. Segments V1-V5 (highlighted in red) show when the videos were recorded (see Suppl. Mater.). 
the first $2 \mathrm{~min}$, to $\sim 0.03 \mathrm{~K} \mathrm{~s}^{-1}$ for $4-130 \mathrm{~min}$. The microstructures seen in Figs. 3 and 4 are indicated by the coloured dots, and the sequence can be fitted with the transformation temperatures $\left(T_{\mathrm{x} 1}\right.$ to $T_{\mathrm{m}}$ ) appropriate to the local $\Phi$. The key calibration points are the narrow interval between $T_{\mathrm{x} 1}$ and $T_{\mathrm{x} 2}$ for the nanocrystalline $(\mathrm{Au}, \mathrm{Cu})_{7} \mathrm{Si}$ phase without grain growth, and the onset of melting at $T_{\mathrm{m}}$. The heating profile is plotted using the nominal temperature of the TEM stage. We assume that this matches the actual sample temperature at $423 \mathrm{~K}$, and that its percentage deviation increases linearly with sample temperature. At $T_{\mathrm{x} 1}(461 \mathrm{~K})$ the nominal temperature is $471 \mathrm{~K}$ ( $2 \%$ higher $)$, and ultimately at $T_{\mathrm{m}}(618 \mathrm{~K})$, it is $673 \mathrm{~K}(8.9 \%$ higher). Over $70 \%$ of the temperature range from RT to $T_{\mathrm{m}}$, the nominal temperature is within the $\pm 5 \%$ accuracy limit claimed for the stage temperature (Fig. S3). The approximate sample temperatures given in $\S 3.2$ are obtained by interpolation in the range from $423 \mathrm{~K}$ to $618 \mathrm{~K}\left(T_{\mathrm{m}}\right)$ (Fig. S3).

\section{References}

[1] W. Klement, R.H. Willens, P. Duwez, Non-crystalline structure in solidified gold-silicon alloys, Nature 187 (1960) 869-870.

[2] J. Schroers, B. Lohwongwatana, W.L. Johnson, A. Peker, Gold based bulk metallic glass, Appl. Phys. Lett. 87 (2005) 061912.

[3] J. Schroers, On the formability of bulk metallic glass in its supercooled liquid state, Acta Mater. 56 (2008) 471-478.

[4] M. Eisenbart, U.E. Klotz, R. Busch, I. Gallino, A colourimetric and microstructural study of the tarnishing of gold-based bulk metallic glasses, Corros. Sci. 85 (2014) 258-269.

[5] M. Eisenbart, On the Processing and the Tarnishing Mechanism of Gold-Based Bulk Metallic Glasses, Dissertation, Univ. Saarland, 2015.

[6] J.H. Na, K.H. Han, G.R. Garrett, M.E. Launey, M.D. Demetriou, W.L. Johnson, Designing color in metallic glass, Sci. Rep. 9 (2019) 3269.

[7] J. Schroers, Q. Pham, A. Peker, N. Paton, R.V. Curtis, Blow molding of bulk metallic glasses, Scripta Mater. 57 (2007) 341-344.

[8] G. Fiore, P. Rizzi, L. Battezzati, Phase constitution and glass formation in an Au-based alloy, J. Alloys Comp. 509S (2011) S166-S169.

[9] J.M. Pelletier, S. Cardinal, J.C. Qiao, M. Eisenbart, U.E. Klotz, Main and secondary relaxations in an Au-based bulk metallic glass investigated by mechanical spectroscopy, J. Alloys Comp. 684 (2016) 530-536.
[10] L.J. Song, M. Gao, W. Xu, J.T. Huo, J.Q. Wang, R.W. Li, W.H. Wang, J.H. Perepezko, Inheritance from glass to liquid: $\beta$ relaxation depresses the nucleation of crystals, Acta Mater. 185 (2020) 38-44.

[11] G. Dalla Fontana, G.L. Fiore, L. Battezzati, Thermodynamics of the $\mathrm{Au}_{49} \mathrm{Ag}_{5.5} \mathrm{Pd}_{2.3} \mathrm{Cu}_{26.9} \mathrm{Si}_{16.3}$ glass-forming alloy, J. Non-Cryst. Solids 382 (2013) 95-98.

[12] P. Zhang, J.J. Maldonis, Z. Liu, J. Schroers, P.M. Voyles, Spatially heterogeneous dynamics in a metallic glass forming liquid imaged by electron correlation microscopy, Nat. Comm. 9 (2018) 1129.

[13] H.S. Chen, Kinetics of low temperature structural relaxation in two (Fe-Ni)-based metallic glasses, J. Appl. Phys. 52 (1981) 1868-1870.

[14] Y. Yue, C.A. Angell, Clarifying the glass-transition behaviour of water by comparison with hyperquenched inorganic glasses, Nature 427 (2004) 717-720.

[15] C.M. Meylan, J. Orava, A.L. Greer, Rejuvenation through plastic deformation of a La-based metallic glass measured by fast scanning calorimetry, J. Non-Cryst. Solids: X 8 (2020) 100051.

[16] G. Fiore, I. Ichim, L. Battezzati, Thermal analysis, fragility and viscosity of Au-based metallic glasses, J. Non-Cryst. Solids 356 (2010) 2218-2222.

[17] H.E. Kissinger, Reaction kinetics in differential thermal analysis, Anal. Chem. 29 (1957) 1702-1706.

[18] J. Orava, A.L. Greer, Kissinger method applied to the crystallization of glassforming liquids: regimes revealed by ultra-fast-heating calorimetry, Thermochim. Acta 603 (2015) 63-68.

[19] S. Pogatscher, P.J. Uggowitzer, J.F. Löffler, In-situ probing of metallic glass formation and crystallization upon heating and cooling via fast differential scanning calorimetry, Appl. Phys. Lett. 104 (2014) 251908.

[20] H.S. Chen, A method for evaluating viscosities of metallic glasses from the rates of thermal transformations, J. Non-Cryst. Solids 27 (1978) 257-263.

[21] S. Pogatscher, D. Leutenegger, J.E.K. Schawe, P. Maris, R. Schäublin, P.J. Uggowitzer, J.F. Löffler, Monotropic polymorphism in a glass-forming metallic alloy, J. Phys.: Condens. Matter 30 (2018) 234002.

[22] A. Blazevic, H.S. Effenberger, K.W. Richter, Phase equilibria in the system $\mathrm{Au}-\mathrm{Cu}-\mathrm{Si}$ and structural characterization of the new compound $\mathrm{Au}_{5 \pm x} \mathrm{Cu}_{2 \pm \chi} \mathrm{Si}$, Intermetal. 46 (2014) 190-198.

[23] J.E.K. Schawe, J.F. Löffler, Existence of multiple critical cooling rates which generate different types of monolithic metallic glass, Nat. Comm. 10 (2019) 1337.

[24] L.C. Chen, F. Spaepen, Analysis of calorimetric measurements of grain growth, J. Appl. Phys. 69 (1991) 679-688.

[25] Y.K. Huang, A.A. Menovsky, F.R. de Boer, Calorimetric analysis of the grain growth in nanocrystalline copper samples, Nanostr. Mater. 2 (1993) 587-595.

[26] Z.J. Evenson, On the Thermodynamic and Kinetic Properties of Bulk Glass Forming Metallic Systems, Dissertation, Univ. Saarland, 2012.

[27] D.A. Porter, K.E. Easterling, M.Y. Sherif, Phase Transformations in Metals and Alloys, 3rd edn, CRC Press, Boca Raton, FL, 2009, pp. 140-142. 
2020-06-18

\section{In-situ TEM study of the crystallization sequence in a gold-based metallic glass}

Ivanov, Yu P.

Elsevier

Ivanov YP, Meylan CM, Panagiotopoulos NT, et al., (2020) In-situ TEM study of the crystallization sequence in a gold-based metallic glass. Acta Materialia, Volume 196, September 2020, pp. 52-60

https://doi.org/10.1016/j.actamat.2020.06.021

Downloaded from Cranfield Library Services E-Repository 